УДК 336.71:338.23(520)

DOI dx.doi.org/10.24866/1813-3274/2020-2/30-38

М. Е. Горчакова ${ }^{1}$, Байкальский государственный университет,

г. Иркутск, Россия

E-mail: GorchakovaME@bgu.ru

\title{
ДЕНЕЖНО-КРЕДИТНАЯ ПОЛИТИКА БАНКА ЯПОНИИ В УСЛОВИЯХ ГЛОБАЛЬНОГО КРИЗИСА
}

Аннотация. Мировая банковская система непрерывно развивается и совершенствуется. Банковские системы отдельных стран модифицируются под влиянием интеграции финансовых отношений государств мира и глобализации в сфере банковского дела. Экономика Японии получила широкое развитие в период так называемого «экономического чуда», во время которого Япония стала второй страной в мире по общему объёму производства, занимая третье место по экспорту продукции. Быстрыми темпами развивается непроизводственный сектор Японии: сфера услуг, финансы, научно-исследовательская деятельность.

Статья посвящена изучению деятельности центрального банка Японии - одного из ведущих мировых финансовых институтов. Выделены организационные принципы функционирования Банка Японии. Рассмотрены три руководящих принципа управления, используемых Банком Японии в процессе его деятельности для выполнения роли центрального банка и достижения таких целей, как поддержание ценовой стабильности и содействие экономическому росту в стране. Банк Японии, будучи первым звеном банковской системы страны, реализует денежно-кредитную политику, применяя комплекс мер, направленных на управление совокупным спросом через условия денежного рынка. В статье отражены инструменты денежно-кредитной политики, применяемые Банком Японии для обеспечения стабильности экономического развития страны. Особое внимание уделяется мерам, предпринятым Банком Японии в связи с кризисом, вызванным пандемией коронавируса COVID-19. Речь идёт о поддержке компаний, пострадавших от последствий коронавируса COVID-19, включая предоставление беспроцентных займов, выдачу гарантий по кредитам малому и среднему бизнесу, пострадавшему от пандемии, субсидии по переводу бизнеса в онлайн. Банк Японии планирует использовать пакет фискальных и монетарных анти-

\footnotetext{
${ }^{1}$ Мария Евгеньевна Горчакова, кандидат экономических наук, доцент, кафедра финансов и финансовых институтов, Байкальский государственный университет, г. Иркутск, Россия.

Для цитирования: Горчакова М. Е. Денежно-кредитная политика банка Японии в условиях глобального кризиса // Азиатско-Тихоокеанский регион: экономика, политика, право. 2020. № 2. С. 30-38.
}

(C) Горчакова М. Е., 2020 
кризисных мер для поддержки экономики страны. Реализация мероприятий необходима для ограничения экономического ущерба от кризисных явлений, вызванных коронавирусом COVID-19, и сглаживания волатильности рынков. Актуальность исследования обусловлена тем, что в условиях финансовой глобализации необходимо учитывать опыт зарубежных банковских систем, особенно в ситуации мирового кризиса, затронувшего экономики всех стран.

Ключевые слова: мировая банковская система, глобализация, банковское дело, Япония, центральный банк, денежно-кредитная политика, операции на открытом рынке, экономическая активность, ликвидность, COVID-19, финансовый кризис, антикризисные меры.

Maria E. Gorchakova ${ }^{1}$, Baikal State University, Irkutsk, Russia

E-mail: begemot.05@mail.ru

\section{JAPAN'S BANK MONETARY POLICY IN THE CONTEXT OF GLOBAL CRISIS}

Abstract. The world banking system is constantly developing and improving. The banking systems of individual countries are modified under the influence of the integration of financial relations between the countries of the world and globalization in banking. The Japanese economy was widely developed during the period of the so-called «economic miracle», during which Japan became the second country in the world in total production volume, ranking third in the export of products. The non-manufacturing sector of Japan is developing rapidly: the service sector, finance, and research.

The article is devoted to the study of the activities of the Central Bank of Japan one of the leading global financial institutions. The organizational principles of the Bank of Japan are highlighted. Three management principles used by the Bank of Japan in the course of its activities to fulfill the role of the central bank and achieve goals such as maintaining price stability and promoting economic growth in the country are considered. The Bank of Japan, being the first link in the country's banking system, implements monetary policy by applying a set of measures aimed at managing aggregate demand through money market conditions. The article reflects the monetary policy instruments used by the Bank of Japan to ensure the stability of the country's economic development.

Particular attention is paid to the measures taken by the Bank of Japan in connection with the crisis caused by the pandemic of the coronavirus COVID-19. It is about

Maria E. Gorchakova, Associate Professor, Associate Professor of the Department of Finance and Financial Institutions, Baikal State University, Irkutsk, Russia.

For citing: Gorchakova M. E. Japan's bank monetary policy in the context of global crisis // PACIFIC RIM: Economics, Politics, Law. 2020. No. 2. P. 30-38. 
supporting companies affected by the consequences of the coronavirus COVID-19, including providing interest-free loans, issuing guarantees for loans to small and mediumsized businesses affected by the pandemic, subsidies for transferring business online. The Bank of Japan plans to use a package of fiscal and monetary anti-crisis measures to support the country's economy. Implementation of measures is necessary to limit the economic damage from the crisis caused by the coronavirus COVID-19, and to smooth out the market volatility.

The relevance of this study is due to the fact that in the context of financial globalization, it is necessary to take into account the experience of foreign banking systems, especially in the situation of the global crisis that affected the economies of all countries.

Keywords: world banking system, globalization, banking, Japan, central bank, monetary policy, open market operations, economic activity, liquidity, COVID-19, financial crisis, anti-crisis measures.

Для современного развития банковского дела характерно сближение определённых параметров функционирования банковских систем разных стран.

Для современной России очень ценен опыт мировой банковской системы. Изучение зарубежного опыта организации банковской деятельности позволит избежать России характерных ошибок и применить передовые технологии банковского дела в отечественной практике. Одной из самых мощных и развитых в мире является банковская система Японии, в связи с чем представляется целесообразным исследование опыта работы центрального банка этой страны - Банка Японии (Bank of Japan) в современных условиях кризиса.

Банк Японии (далее - Банк) был создан в соответствии с Законом о Банке Японии, принятом в 1882 г., и начал свою деятельность 10 октября 1882 г. Этот закон был полностью пересмотрен с целью подготовки действующего Закона о Банке Японии от 1997 г., который вступил в силу в апреле 1998 г.

Банк является юридическим лицом, созданным на основании Закона о Банке Японии. Его заявленный капитал составляет 100 миллионов иен. Выпущенный акционерный капитал принадлежит государству (55 процентов) и частному сектору (45 процентов).

Банк получает большую часть своей прибыли от процентных доходов и доходов от продажи своих активов, таких как японские государственные облигации. В тех случаях, когда эта прибыль превышает расходы на деловые операции Банка (включая стоимость производства банкнот и расходы на персонал), налоги и дивиденды, оставшаяся часть (весь чистый доход) выплачивается правительству.

Закон о Банке Японии определяет основные цели банка следующим образом: статья 1 предусматривает, что Банк обязан выпускать банкноты, осуществлять ва- 
лютный контроль и поддерживать стабильность финансовой системы, а статья 2 предусматривает, что валютный контроль должен быть направлен на достижение стабильности цен, способствуя тем самым устойчивому развитию национальной экономики.

Организационные принципы Банка Японии представляют собой набор фундаментальных ценностей, которые должны соблюдаться им как центральным банком Японии. Должностные лица и сотрудники банка должны всегда соблюдать эти принципы при ведении деловых операций. Банк обеспечит общественное доверие путём надлежащего проведения своей политики и деловых операций в соответствии со следующими организационными принципами [2].

Банк продвигает общественные интересы, выполняя основные цели, предусмотренные Законом о Банке Японии.

Банк должен демонстрировать надлежащую ответственность в своей политике и деловых операциях посредством различных внешних связей.

Банк должен стремиться к совершенству в предоставлении услуг центрального банка, должным образом реагируя на изменения в окружающей среде.

Банк должен обеспечивать честность при исполнении обязанностей каждым должностным лицом и работником, требуя соблюдения высоких моральных стандартов.

Банк должен эффективно и результативно использовать ресурсы управления при проведении деловых операций и организационном управлении.

В современных условиях, окружающих центральные банки, продолжается глобализация экономики и финансов. Между тем инновации и применение информационных технологий, таких как цифровизация, ускорились, и это начало оказывать широкое и разнообразное воздействие на экономическую и финансовую деятельность. В Японии экономические и финансовые последствия структурных социальных изменений, таких как сокращение и старение населения, возрастают. Эти условия ставят перед центральными банками всё более широкий круг проблем, и для них становится всё более важным адекватно реагировать на изменения в окружающей среде.

Исходя из вышеизложенного понимания, чтобы должным образом выполнять свою роль центрального банка Японии, Банк Японии установил следующие три руководящих принципа управления [2].

\section{А. Сплочённая работа для выполнения своих задач.}

Миссия Банка Японии заключается в достижении стабильности цен и обеспечении стабильности финансовой системы. Для достижения стабильности цен Банк установил целевой показатель стабильности цен на уровне $2 \%$ с точки зрения изменения индекса потребительских цен (далее - ИПЦ) в годовом исчислении. Он будет продолжать слаженно работать над выполнением этих задач, а его сотрудники раз- 
деляют понимание того, что это способствует интересам общества. В связи с этим для Банка важно довести до сведения общественности свою политику и деловые операции в доступной для понимания форме и внимательно прислушиваться к стороннему мнению. Признавая это, Банк будет и дальше расширять свои связи как внутри Японии, так и за её пределами.

В. Повышение гибкости при реагировании на изменяющуюся среду.

Окружающая среда центральных банков претерпела значительные изменения, и поэтому для них стало важно повысить гибкость реагирования на эти изменения. С этой целью Банк укрепляет свои операционные механизмы реагирования на такие изменения посредством инициатив, в том числе непрерывного пересмотра своих деловых операций, повышения операционной эффективности и эффективного использования ресурсов управления. Это также обеспечит персонал, необходимый для эффективного осуществления его бизнес-операций и организационного управления, за счёт привлечения людских ресурсов с высокой степенью банковского опыта.

С. Стабильное выполнение бизнес-операций.

Миссии Банка осуществляются посредством выполнения широкого спектра операций центрального банка; стабильность и честность, с которой он выполняет эти операции, являются тем, что лежит в основе доверия общественности к Банку. Между тем, центральные банки сталкиваются и, как ожидается, будут и впредь сталкиваться с растущим рядом проблем. Учитывая эти соображения, Банк обеспечит стабильное выполнение бизнес-операций, должным образом управляя своими операционными рисками, сохраняя и дополнительно повышая операционную надёжность и индивидуальный опыт своих сотрудников, которые культивировались в результате их многолетней деятельности на рабочем месте. Он также будет продолжать обеспечивать полную честность, с которой его должностные лица и сотрудники выполняют свои обязанности.

Являясь центральным банком Японии, Банк Японии осуществляет денежнокредитную политику для достижения стабильности цен, тем самым способствуя устойчивому развитию национальной экономики. С этой целью Банк Японии стремится к достижению целевого уровня краткосрочных и долгосрочных процентных ставок и приобретает активы, в основном посредством операций на открытом рынке.

Операции на открытом рынке являются основным инструментом Банка Японии на денежном рынке. Банк контролирует объём средств на финансовых рынках, поощряя увеличение или уменьшение остатка на текущих счетах финансовых учреждений в Банке. Этот контроль достигается, например, путём увеличения или уменьшения кредитования Банком финансовых учреждений или путём покупки или продажи финансовым учреждениям финансовых активов, таких как японские государственные ценные бумаги (JGS). 
Когда Банк покупает активы, такие как JGS, которыми владеют финансовые учреждения, средства поступают на денежный рынок (операции по предоставлению средств). Напротив, когда Банк продаёт активы, которые он держит, такие как JGS, финансовым учреждениям, средства поглощаются с денежного рынка.

Для обеспечения надлежащих операций на денежном рынке Банк постоянно и тщательно следит за развитием событий на финансовых рынках в стране и за рубежом, а также обменивается мнениями с участниками рынка, когда это необходимо.

Основная позиция в отношении денежно-кредитной политики определяется Советом по денежно-кредитной политике Банка (Bank's Policy Board at Monetary Policy Meetings). Совет состоит из девяти членов: управляющего, двух заместителей управляющего и шести других членов.

Важные вопросы, касающиеся мер политики Банка, деловых операций и организационного управления, решаются большинством голосов Совета по политике. Среди них основная позиция Банка в отношении денежно-кредитной политики определяется на заседаниях по денежно-кредитной политике, проводимых восемь раз в год. На каждом совещании по денежно-кредитной политике Совет по политике обсуждает и решает такие вопросы, как позиция Банка в отношении денежнокредитной политики на ближайшее будущее.

При проведении денежно-кредитной политики Банку предоставляется высокая степень автономии. Это отражает уроки, извлечённые из истории централизации банковской деятельности, когда возникали случаи серьёзной инфляции в случае нарушения автономии центрального банка.

В то же время, поскольку денежно-кредитная политика оказывает сильное влияние на жизнь людей и экономическое и финансовое положение страны, Банк обязан разъяснять содержание своих политических решений и основы своих суждений. Соответственно, Банк Японии работает по нескольким направлениям коммуникации с общественностью.

Какое влияние может оказать вспышка нового коронавируса (COVID-19) на денежно-кредитную политику, проводимую Банком Японии?

Следует отметить, что в последнее время экономическая активность в Японии была слабой, главным образом из-за воздействия вспышки коронавируса (COVID-19). В частности, экспорт и производство сократились из-за замедления темпов роста в зарубежных экономиках с 2019 г., а также из-за снижения внешнего спроса, главным образом из Китая, и влияния на глобальную цепочку поставок прекращения производства, в основном в Китае. Кроме того, сократилось количество въезжающих туристов, и были ограничены возможности проводить внутренние мероприятия. Эти события привели к ухудшению условий ведения бизнеса в смежных отраслях. Что касается цен, то годовой показатель изменения индекса потребительских цен (ИПЦ) находится в диапазоне $0,5-1,0 \%$. 
Учитывая эти события, Банк Японии счёл целесообразным усилить смягчение денежно-кредитной политики посредством дальнейшего достаточного предложения средств путём проведения различных операций, включая покупку японских государственных облигаций (JGBs) и операции по предоставлению средств в долларах США, меры по содействию корпоративному финансированию, включая введение новой операции, и активные покупки биржевых фондов (ЕTF) и инвестиционных фондов недвижимости Японии (J-REIT). Банк Японии примет эти меры с целью сделать всё возможное для обеспечения бесперебойного корпоративного финансирования и поддержания стабильности на финансовых рынках, тем самым предотвращая ухудшение настроений фирм и домашних хозяйств.

Для этого в марте 2020 г. Банк Японии принял решение о следующем [2].

1) Дальнейшая достаточная поставка средств для финансовой системы.

Банк в настоящее время предоставит более высокий объём денежных средств в иенах, используя активные покупки JGB и другие операции, а также ряд других мер.

Что касается ликвидности в долларах США, согласованной с Банком Канады, Банком Англии, Европейским центральным банком, Федеральной Резервной Системой и Швейцарским национальным банком, - поддерживая операции в долларах США, Банк Японии снизил ставку по кредитам на 0,25 процента и предлагает доллары США еженедельно с 84-дневным сроком погашения, в дополнение к однонедельным срокам погашения, предлагаемым в настоящее время.

2) Меры по содействию корпоративному финансированию:

a) Введение специальных операций по предоставлению средств для содействия корпоративному финансированию с целью борьбы с новым коронавирусом (COVID-19).

Банк единогласно решил ввести новую операцию по предоставлению кредитов под корпоративный долг (около 8 трлн иен на конец февраля 2020 г.) в качестве обеспечения под процентную ставку $0 \%$ со сроком погашения до одного года. Эта операция будет проводиться до конца сентября 2020 г.;

б) Увеличение покупок корпоративных облигаций.

Банк принял решение об увеличении верхнего предела на покупку корпоративных облигаций в общей сложности на 2 трлн иен и проведении покупок с верхним лимитом их непогашенных сумм, составляющим около 3,2 трлн иен и около 4,2 трлн иен соответственно. Дополнительные покупки будут продолжаться до конца сентября 2020 г.

3) Активные покупки активов биржевых инвестиционных фондов (ЕTF) и активов инвестиционных трастов недвижимости (J-REIT).

Банк решил активно покупать ETF и J-REIT, чтобы их непогашенные суммы увеличивались в годовом исчислении с верхним пределом около 12 трлн иен и около 180 млрд иен, соответственно. 
Банк решил придерживаться следующего руководства по рыночным операциям в течение промежуточного периода.

Краткосрочная политика процентной ставки. Банк применяет отрицательную процентную ставку в размере минус $0,1 \%$ к остаткам на текущих счетах, находящихся в финансовых учреждениях Банка.

Долгосрочная процентная ставка. Банк будет покупать JGB, чтобы доходность по 10-летним JGB оставалась на уровне около нуля процентов. При этом доходность может двигаться в некоторой степени вверх и вниз, в основном в зависимости от изменений в экономической активности и ценах. Что касается количества приобретаемых JGB, то Банк будет осуществлять покупки гибким образом, так что их непогашенная сумма будет увеличиваться в годовом исчислении примерно на 80 трлн иен.

Банк продолжит количественное и качественное ослабление денежной массы, направленное на достижение цели стабильности цен в $2 \%$, если это необходимо для поддержания этой цели на стабильной основе. Он будет продолжать расширять денежную базу до тех пор, пока годовой темп роста наблюдаемого индекса потребительских цен (ИПЦ) не превысит 2 \% и стабильно останется выше целевого показателя. Что касается процентных ставок, Банк ожидает, что краткосрочные и долгосрочные процентные ставки останутся на своих нынешних или более низких уровнях до тех пор, пока станет необходимым обратить пристальное внимание на возможность того, что импульс к достижению цели стабильности цен будет потерян. Банк будет внимательно следить за воздействием COVID-19 в настоящее время и без колебаний примет дополнительные меры по смягчению денежнокредитной политики в случае необходимости.

Банк признаёт, что принятые сегодня меры по смягчению денежно-кредитной политики будут способствовать поддержке экономической и финансовой деятельности в сочетании с различными мерами, предпринимаемыми правительством Японии, а также правительством и центральным банком каждой страны в ответ на вспышку COVID-19.

Что касается перспектив, то экономическая активность Японии, вероятно, в настоящее время будет оставаться слабой, в основном под влиянием вспышки COVID-19. После этого ожидается возврат к умеренной расширяющейся тенденции, поддерживаемой благотворным циклом от доходов к расходам, причём влияние вспышки COVID-19 ослабевает, главным образом, благодаря мерам, принятым каждой страной. Темпы изменения ИПЦ в годовом исчислении, вероятно, будут в настоящее время несколько слабыми, отчасти из-за последствий снижения цен на сырую нефть. После этого ожидается постепенный рост, когда экономика вернется к умеренной тенденции к росту.

Что касается рисков, связанных с будущим, существовала значительная неопределённость в отношении последствий вспышки COVID-19, а также в отноше- 
нии размеров и продолжительности их воздействия на внутреннюю и внешнюю экономику. Кроме того, остаются другие риски, такие как протекционистские действия и их последствия, а также геополитические риски. Похоже, что риски ухудшения ситуации возрастают, и необходимо также обратить пристальное внимание на их влияние на развитие мировых финансовых рынков, а также на настроения фирм и домашних хозяйств в Японии.

\section{Список литературы}

1. Оношко, О. Ю. Мировые банковские системы. - Иркутск : Изд-во БГУЭП, 2005. $-496 \mathrm{c}$.

2. Bank of Japan. - URL: https:/www.boj.or.jp/en/index.htm/ (дата обращения: 03.04.2020).

\section{References}

1. Onoshko O. U. Mirovye bankovskie sistemy [World banking systems]. Irkutsk: BGUEP Publ., 2005. 496 p.

2. Bank of Japan. Available at: https://www.boj.or.jp/en/index.htm/ (accessed 03 April 2020). 